\title{
The effect of a maternal training programme on early childhood development in Egypt
}

Heba Mohammed, ${ }^{1}$ Omaima El-Gibaly, ${ }^{1}$ Eman Monazea, ${ }^{1}$ Medhat Saleh ${ }^{1}$ and Hanaa Mohammed ${ }^{2}$

${ }^{1}$ Public Health and Community Medicine, Faculty of Medicine, Assiut University, Egypt. ${ }^{2}$ Faculty of Medicine, Assiut University, Egypt. (Correspondence to: Heba Mohammed: dr.heba.mahmoud@hotmail.com).

\begin{abstract}
Background: The initial years of life, particularly the first two years, are considered the most important for brain development and timely interventions profoundly affect the health of the child and families.

Aims: This study aimed to determine the effect of maternal health education on motor, social and cognitive development in infants less than two years old, and to identify the factors that could affect normal development.

Methods: Two hundred and ten mothers and their infants (109 interventions, 101 controls) were recruited from maternal and child health centres in Assiut Governorate, Egypt, in 2017. The maternal training programme has been taught to mothers of infants in intervention groups twice per month and up to five months' duration; however, routine services are provided to control groups only. Bivariate and multivariable analyses were performed to identify the most important predictors of normal development.

Results: There were significant improvements in early childhood developmental domains for the intervention groups after five months comparable to the base line assessment. Percent of normal development among intervention groups in communication subscale increased from $46.8 \%$ to $76 \%$ to $97.9 \%$ compared to $50.5 \%$ to $46.8 \%$ to $57.4 \%$ in the control groups (baseline, after two month and after five months assessment respectively). The intervention was a significant predictor in normal development.

Conclusions: There was an improvement in early childhood developmental domains for the intervention groups after applying maternal training programme. Designing educational interventions for routine health care services that reach all children will provide mothers with the opportunity for improvement in early childhood developmental.

Keywords: early childhood development; maternal training; intervention; ASQ-3, Egypt

Citation: Mohammed H; El-Gibaly O; Monazea E; Saleh M; Mohammed H. The effect of a maternal training programme on early childhood development in Egypt. East Mediterr Health J. 2019;25(8):575-582. https://doi.org/10.26719/emhj.18.065

Received: 04/02/18; accepted: 30/07/18

Copyright @ World Health Organization (WHO) 2019. Some rights reserved. This work is available under the CC BY-NC-SA 3.0 IGO license (https:// creativecommons.org/licenses/by-nc-sa/3.0/igo).
\end{abstract}

\section{Introduction}

Child development is defined as those aspects of growth that involve physical, mental, emotional and social changes (1). Developmental delay is a condition in which the child is not developing and/or does not reach skills in accordance with the sequence of predetermined stages (2). Approximately 5-15\% of all children in the general population show developmental disorders (3) and are classified into different categories (gross motor, fine motor, social skill, speech and mental skill) (4). A study undertaken in the United States of America reported that nearly one in six children had developmental delays (5). Systematic reviews of the scientific literature demonstrate effectiveness of early childhood development programmes in preventing developmental delay (6).

Following the emphasis on home environment and the importance of the role of parents in educating children using toys appropriate to their age, Nagar and Sharma (2009) found that there was a statistically significant relationship between developmental age and psychomotor development concerning home environment (7). In an intervention on the importance of the role of playing in improving developmental skills in infants between 13 and 17 months of age, a significant relationship was revealed in improving mental and motor developmental skills in the intervention group rather than in the control group (8). Increasing detection of developmental disorders at an earlier age through intervention services are cost effective and improve the developmental prognosis, resulting in short and longterm benefits (9). Currently, there is little awareness about the problem of delayed development and there is no strategy to improve development of disadvantaged children or how to provide mothers with relevant skills in early childhood developmental. This study assessed the impact of early childhood developmental support services on caregivers (mothers) with regard to motor, social and cognitive development of children and to identify those factors that could affect normal child development.

\section{Methods}

\section{Study design and setting}

A pre-test / post-test control group study was conducted in Assiut Governorate, Egypt at two urban and two rural maternal and child health centres. Data were collected from July 2016 to March 2017. 


\section{Sampling technique}

The sites were chosen based on data and approvals from the Ministry of Health, since these sites have sufficient numbers of patients, availability of well-trained nursing staff, equipped for the conduct of health education classes, proper assessment of growth and development, and practical distance from Assiut University. Mothers and their children were recruited from immunization clinics of urban and rural maternal and child health centres (two urban and two rural), randomly assigned into intervention and control groups, and excluding children with congenital and neurological diseases.

\section{Sample size}

Two hundred and ten participants were interviewed at the baseline survey (109 interventions, 101 controls); $190(90.5 \%)$ successfully completed the study after two months (96 interventions, 94 controls), and 188 (89.5\%) successfully completed the study after four months (94 intervention, 94 control). Twenty-two (10.5\%) women dropped out during the study period after baseline assessment due to refusal to complete to the end line assessment, especially those in urban settings and those travelling outside their countries. Rural areas had lower dropout rate because rural outreach workers (Raedat Rifiyat) had communication with most mothers and therefore reminded them before each class.

\section{Study design}

Data were collected using two questionnaires (one for the mothers and the other for children). For mothers the questionnaire was semi-structured and administered through personal interview. Information collected included:

- Background information of the child and mother (age of the mother, marital status, education, occupation, father's age, education, occupation, child age, sex and birth weight).

- Evidence of maternal social support (help from husband, as well from immediate family and others).

- Pattern of breast feeding, time of start breast feeding, exclusive breast feeding, and foods given to the baby after six months.

- Child morbidity and exposure to any health problems in the previous two months.

Children were interviewed using the Ages and Stages Questionnaires, 3rd edition ASQ-3. ASQ-3, which is a screening tool that assesses a child's development from 2 to 60 months of age; it evaluates five domains of development:

1. Communication: this refers to a child's language, listening and comprehension skills.

2. Gross motor: this refers to a child's use and coordination of arm and legs.

3. Fine motor: this refers to a child's movements and coordination of hands and fingers.
4. Problem solving: this refers to a child's problem-solving, learning and play skills.

5. Personal-social: this refers to a child's self-learning skills and interaction skills with others.

Each domain has a set of six items and parents rate the most appropriate answer for each skill: "Yes," "Sometimes," "Not yet," with point values of 10, 5, or o, respectively. The total score for each skill is obtained by adding the scores of the six items and comparing with the cut-off points, which vary for all skills and ages (3). The ASQ-3 English version was translated into Arabic and back translated to ensure accuracy. For each domain results are reported as "normal" or "suspect developmental delay", indicating that a particular milestone attainment was not evident and further evaluation is recommended.

Cut-off points for each subscale are provided to indicate whether the score falls within a normal developmental range based on chronological age, or if it represents "at risk" or delayed development. ASQ-3 has established reliability and validity for practical use in a written questionnaire and has widespread use in clinical and research settings $(10,11)$; Cronbach's alpha for total score was 0.86 .

Children in intervention groups were entered into maternal health education programmes; routine services were provided to control groups only.

\section{Description of intervention}

The period of intervention was five months and was delivered by the researchers and assisted by two trained nurses. Approximately 10-15 mothers and their children were present per class, creating 3 groups in each intervention site. The groups were classified according to child age $(2-<6$ months, $6-<9$ months and $9-<12$ months) to allow mothers to receive age-related information and absorb the information received. Every mother in the intervention groups received twice monthly health education classes, resulting in a total of 60 classes for the intervention.

Education classes included PowerPoint presentations and literature prepared by the researchers based on the book "Ages and Stages Learning Activities 0-5 years" (12), which contains pictures illustrating various aspects of development; for example pictures of children in activities that would promote motor development (crawling, pushing, holding, etc.) and cognitive development (naming objects, looking at a book, playing matching games, etc.).

Each session lasted approximately two to three hours. For one hour trainers explained the different aspects of child development for each age group and demonstrated how these could be promoted through play and interaction. Mothers also learned how to use everyday activities (e.g. bathing, dressing the child) and everyday household tasks (e.g. laundry, meal preparation) to promote interaction and development. For the remaining two hours the trainers and mother played with the child in ways that would promote development. All children 
at the intervention and control sites were assessed by ASQ-3 according to their age after two months and after five months from the baseline assessment.

\section{Statistical analysis}

SPSS software version 20 was used for analyses. Bivariate analysis and t-test were used for comparison of the mean; Chi-square test was used for comparison of proportions between intervention and control groups; McNemar test was used for comparisons of proportion within the same group before and after intervention; and multivariable logistic regression analysis was performed to identify the most important predictors of normal childhood development. $P$ value $<0.05$ was considered statistically significant.

\section{Ethical approval}

Informed and written consent was obtained from the mothers of all the children enrolled in the study. Ethical approval was taken for conducting this study from the Ethics Review Committee, Faculty of Medicine, Assiut University, Egypt. Approval from the Ministry of Health and Population from each study site was also taken. For ethical considerations, the end-line survey was followed by health education for mothers in the control groups. The original copy of the English version of ages and stages questionnaire was purchased.

\section{Results}

A total of 210 infants and their mothers were included in the study (109 interventions and 101 controls). There was no statistically significant difference in child's age, gender, residence, mother's age, education, occupation, father age and education ( $P \geq 0.05)$ between intervention and control groups at the base line assessment. The mean age of children was $5.7 \pm 3.4$ months in intervention groups and $6.1 \pm 3.3$ months in control groups; $50.5 \%$ and $49.5 \%$ were males in intervention and control group respectively; mean age of the mother was $28.8 \pm 4.4$ years and $25.5 \pm 3.7$ years in intervention and control group respectively. Mean birth weight was $3018.23 \pm 383.96 \mathrm{~g}$ and $2975.36 \pm 394.132 \mathrm{~g}$ among intervention and control groups respectively, and there was no statistical significance.

95.5\% of mothers in interventions group had breast fed their infant compared to $96 \%$ in the control groups; $33.7 \%$ of mothers in the interventions group started breast feeding in the first 30 minutes after birth compared to $33 \%$ in the controls; and $69.7 \%$ of mothers in the intervention groups were exclusively breast feeding compared to $69.3 \%$ in the control groups. The food given to the infant after 6 months from birth were milk products followed by vegetables and bread categories.

Nearly $60 \%$ of the intervention groups were exposed to health problems in the previous two months compared to $55.5 \%$ in the control groups; there was no statistical significance. The most common health problems were gastroenteritis, common cold and fever.
There was no statistically significant difference between the intervention and control groups at the baseline assessment regarding communication, gross motor, fine motor, problem solving and personal social skills. After two months and after five months from the base line, there were significant differences between interventions and controls regarding the five developmental subscales. In intervention groups, percent of normal child development in communication subscale increased from $46.8 \%$ to $76 \%$ to $97.9 \%$ compared to $50.5 \%$ to $46.8 \%$ to $57.4 \%$ in the control groups (baseline, after two month and after five months assessment respectively) (Table 1).

There was a significant improvement in child development in the intervention groups in all domains after five months comparable to the base line assessment $(P<0.001)$. Percent of suspect developmental delay was $52 \%, 63.8 \%, 54.3 \%, 52 \%$ and $50 \%$ regarding communication, gross motor, fine motor skills, problem-solving personal social skills, respectively, at the baseline in interventions groups, compared to $2.2 \%, 23.4 \%, 14.9 \%, 3.2 \%$ and $5.3 \%$ after applying the maternal health education program (Table 2).

Logistic regression analysis for early childhood developmental domains at the end line assessment (after five months) found that intervention was a significant predictor in normal child development in communication, growth motor, fine motor, problem solving and personal social $(\mathrm{OR}=3.42,3,15,4.23,4.21$, 4.59 respectively). In addition, maternal social support in child raising (husband, relatives, neighbours and friends) was a significant predictor in communication, personal social domains (Table 3).

\section{Discussion}

Child development is difficult to measure because of its nature and influence by continuous biomedical and/or sociocultural factors. Most well conducted studies on psychosocial stimulation programmes have resulted in immediate benefits to children's development and some have shown long-term benefits in social behaviour and school achievement (8).

We believe that our intervention also benefited mothers, since health education brought mothers together and facilitated a sharing of experiences, ideas and general interaction. Mothers gained knowledge of better care for their children and they valued their new skills in dealing with different items of early childhood developmental. The intervention effect showed that children in intervention groups had a marked significant increase in the achievement of normal developmental milestones compared to children in the control groups, which was shown to be highly significant in the multiple regression analysis.

Consistent with our results, a study done in northeast Brazil to improve cognitive and motor development in a community-based intervention (the intervention comprised ten weekly visits and three workshops over 


\begin{tabular}{|c|c|c|c|c|c|c|}
\hline \multirow[t]{2}{*}{ Subscale } & \multicolumn{2}{|c|}{ Baseline } & \multicolumn{2}{|l|}{ After 2 months } & \multicolumn{2}{|c|}{ After 5 months } \\
\hline & $\begin{array}{c}\text { Intervention } \\
(\mathrm{N}=109, \%)\end{array}$ & $\begin{array}{c}\text { Control } \\
(\mathrm{N}=101, \%)\end{array}$ & $\begin{array}{c}\text { Intervention } \\
(\mathrm{N}=96, \%)\end{array}$ & $\begin{array}{c}\text { Control } \\
(\mathrm{N}=94, \%)\end{array}$ & $\begin{array}{l}\text { Intervention } \\
(\mathrm{N}=94, \%)\end{array}$ & $\begin{array}{c}\text { Control } \\
(\mathrm{N}=94, \%)\end{array}$ \\
\hline \multicolumn{7}{|l|}{ Communication } \\
\hline Normal development & $51(46.8)$ & $51(50.5)$ & $73(76.0)$ & $44(46.8)$ & $92(97.9)$ & $54(57.4)$ \\
\hline At risk of disorder & $46(42.2)$ & $39(38.6)$ & $22(22.9)$ & $42(44.7)$ & $2(2.1)$ & $39(41.5)$ \\
\hline Delayed development & $12(11.0)$ & $11(10.9)$ & $1(1.1)$ & $8(8.5)$ & $0(0.0)$ & $1(1.1)$ \\
\hline$P$-value* & \multicolumn{2}{|c|}{0.85} & \multicolumn{2}{|c|}{0.001} & \multicolumn{2}{|c|}{$<0.001$} \\
\hline \multicolumn{7}{|l|}{ Gross motor } \\
\hline Normal development & $39(35.8)$ & $37(36.6)$ & $55(57.3)$ & $37(39.4)$ & $72(76.6)$ & $51(54.3)$ \\
\hline At risk of disorder & $41(37.6)$ & $37(36.6)$ & $28(29.2)$ & $38(40.4)$ & $17(18.1)$ & $31(33.0)$ \\
\hline Delayed development & $29(26.6)$ & $27(26.7)$ & $13(13.5)$ & $19(20.2)$ & $5(5.3)$ & $12(12.8)$ \\
\hline$P$-value* & \multicolumn{2}{|c|}{0.99} & \multicolumn{2}{|c|}{0.04} & \multicolumn{2}{|c|}{0.005} \\
\hline \multicolumn{7}{|l|}{ Fine motor } \\
\hline Normal development & $51(46.8)$ & $40(39.6)$ & $68(70.8)$ & $38(40.4)$ & $80(85.1)$ & $60(63.8)$ \\
\hline At risk of disorder & $48(44.0)$ & $51(50.5)$ & $22(22.9)$ & $51(54.3)$ & $13(13.8)$ & $31(33.0)$ \\
\hline Delayed development & $10(9.2)$ & $10(9.9)$ & $6(6.2)$ & $5(5.3)$ & $1(1.1)$ & $3(3.2)$ \\
\hline$P$-value* & \multicolumn{2}{|c|}{0.57} & \multicolumn{2}{|c|}{0.001} & \multicolumn{2}{|c|}{0.004} \\
\hline \multicolumn{7}{|l|}{ Problem solving } \\
\hline Normal development & $51(46.8)$ & $46(45.5)$ & $77(80.2)$ & $47(50.0)$ & $91(96.8)$ & $42(44.7)$ \\
\hline At risk of disorder & $53(48.6)$ & $46(45.5)$ & $19(19.8)$ & $41(43.6)$ & $3(3.2)$ & $49(52.1)$ \\
\hline Delayed development & $5(4.6)$ & $9(8.9)$ & $\mathrm{o}(0.0)$ & $6(6.4)$ & $0(0.0)$ & $3(3.2)$ \\
\hline$P$-value* & \multicolumn{2}{|c|}{0.45} & \multicolumn{2}{|c|}{0.001} & \multicolumn{2}{|c|}{$<0.001$} \\
\hline \multicolumn{7}{|l|}{ Personal social } \\
\hline Normal development & $56(51.4)$ & $50(49.5)$ & $77(80.2)$ & $43(45.7)$ & $89(94.7)$ & $49(52.1)$ \\
\hline At risk of disorder & $38(34.9)$ & $37(36.6)$ & $17(17.7)$ & $39(41.5$ & $5(5 \cdot 3)$ & $40(42.6)$ \\
\hline Delayed development & $15(13.8)$ & $14(13.9)$ & $2(2.1)$ & $12(12.8)$ & $0(0.0)$ & $5(5 \cdot 3)$ \\
\hline$P$-value* & \multicolumn{2}{|c|}{0.96} & \multicolumn{2}{|c|}{0.001} & \multicolumn{2}{|c|}{$<0.001$} \\
\hline
\end{tabular}

a four-month period) was associated with significant improvements in cognitive and motor development (8). Our study found significant percent increases in communication, fine and gross motor, problem solving and personal social skills for the intervention groups compared to control groups two months and five months after the intervention. This was compatible with results of the study by Rezaeian et al. (1), which investigated the effect of implementation of evidence-based care package on the gross motor development on 1-12 months old infants, and the study was also conducted in the Islamic Republic of Iran among 12-month-old infants on motor skills (13). Our study supports the role of playing and learning to improve early childhood developmental domains, consistent with a study by Miquelote et al. (14) on the effect of the home environment on motor and cognitive behaviour of infants aged three to 18 months in Brazil. A quasi-experimental study by Sajedi and Barati (15) investigated the effect of perceptual motor training on motor skills of preschool children. After 15 onehour training sessions over two months, a significant statistical improvement was observed in motor skills.

In our study, the percentage of suspected development delay at the baseline in interventions groups was consistent with a study carried out by Kyerematen et al. (16) on the application of the ASQ in child development in a low-income Peruvian shantytown population. Of the 129 children in the study (average age $22 \pm 6.8$ months), 


\begin{tabular}{|c|c|c|c|c|c|c|}
\hline \multirow[t]{2}{*}{ Subscale } & \multicolumn{2}{|c|}{ Intervention } & \multirow[t]{2}{*}{ P-value* } & \multicolumn{2}{|c|}{ Control } & \multirow[t]{2}{*}{ P-value } \\
\hline & $\begin{array}{c}\text { Baseline } \\
\text { (N, \%) }\end{array}$ & $\begin{array}{l}\text { End line } \\
(\mathbf{N}, \%)\end{array}$ & & $\begin{array}{l}\text { Baseline } \\
\text { (N, \%) }\end{array}$ & $\begin{array}{c}\text { End line } \\
(\mathbf{N}, \%)\end{array}$ & \\
\hline \multicolumn{7}{|c|}{ Communication } \\
\hline Normal & $45(47.9)$ & $92(97.8)$ & $<0.001$ & $48(51.1)$ & $54(57.4)$ & 0.33 \\
\hline Suspect & $49(52.1)$ & $2(2.2)$ & & $46(48.9)$ & $40(42.6)$ & \\
\hline \multicolumn{7}{|c|}{ Gross motor } \\
\hline Normal & $34(36.2)$ & $72(76.6)$ & $<0.001$ & $35(37.2)$ & $51(54 \cdot 3)$ & 0.01 \\
\hline Suspect & $60(63.8)$ & $22(23.4)$ & & $59(62.8)$ & $43(45.7)$ & \\
\hline \multicolumn{7}{|l|}{ Fine motor } \\
\hline Normal & $43(45.7)$ & $80(85.1)$ & $<0.001$ & $35(37.2)$ & $60(63.8)$ & 0.001 \\
\hline Suspect & $51(54.3)$ & $14(14.9)$ & & $59(62.8)$ & $34(36.2)$ & \\
\hline \multicolumn{7}{|c|}{ Problem solving } \\
\hline Normal & 45 (47.9) & $91(96.8)$ & $<0.001$ & $43(45.7)$ & $42(44.7)$ & 1.0 \\
\hline Suspect & $49(52.1)$ & $3(3.2)$ & & $51(45 \cdot 3)$ & $52(55.3)$ & \\
\hline \multicolumn{7}{|c|}{ Personal social } \\
\hline Normal & $47(50.0)$ & $89(94.7)$ & $<0.001$ & $47(50.0)$ & $49(52.1)$ & 0.86 \\
\hline Suspect & $47(50.0)$ & $5(5.3)$ & & $47(50.0)$ & 45 (47.9) & \\
\hline
\end{tabular}

Analysis conducted on the children who complete the study in the end line survey (94 in intervention and 94 in control groups)

$38.7 \%$ had suspect results for at least one of the five scales, namely communication scale ( $15.5 \%)$, gross motor (3.8\%), fine motor $(10 \%)$, problem solving $(13.9 \%)$ and the personal-social scale (5.4\%).

A study in the Islamic Republic of Iran by Sajedi et al. (17) using the ASQ showed Iranian children delayed in the communication, gross motor, fine motor, problem-solving and social-personal domains (3.87\%, 4.04\%, 4.31\%, 4.15\% and $3.69 \%$, respectively). Alptekin (18) reported that the prevalence of developmental delay by using the ASQtransforming rehabilitation (ASQ-TR) during childhood in Turkey was $6.4 \%$ in a community-based sample consisting of children aged 3-60 months. Another study, using the Norwegian ASQ cut-off points among infant aged 4-12 months, suggested that between $5.7 \%$ and $7.0 \%$ of young children had suspect developmental delay (19).

In addition, a cross-sectional study of 510 kindergartens (age group 24-60 months) in the east of Menuofia Governorate, Egypt, found that the prevalence of suspect developmental delay among the studied children was $2.9 \%, 0 \%, 1.7 \%, 2.2 \%$, and $0.6 \%$ regarding communication, gross motor, fine motor, problem-solving, skills, personal social skills, respectively (20). Differences between the above studies may be due to variations in age groups, study design and other factors such as the nutritional status of children.

Moreover, beside the intervention, maternal social support was found to be another predictor for child development in the communication and personal

\begin{tabular}{|c|c|c|c|c|c|}
\hline predictors & $\begin{array}{c}\text { Communication } \\
\text { OR } \\
(95 \% \mathrm{CI})\end{array}$ & $\begin{array}{c}\text { Growth motor } \\
\text { OR } \\
(95 \% \mathrm{CI})\end{array}$ & $\begin{array}{c}\text { Fine motor } \\
\text { OR } \\
(95 \% \mathrm{CI})\end{array}$ & $\begin{array}{c}\text { Problem solving } \\
\text { OR } \\
(95 \% \mathrm{CI})\end{array}$ & $\begin{array}{c}\text { Personal-social } \\
\text { OR } \\
(95 \% \mathrm{CI})\end{array}$ \\
\hline $\begin{array}{l}\text { Groups } \\
\text { (ref: intervention) }\end{array}$ & $\begin{array}{c}3.42 \\
(2.02-7.66)^{* *}\end{array}$ & $\begin{array}{c}3.15 \\
(1.51-6.59)^{*}\end{array}$ & $\begin{array}{c}4.23 \\
(2.39-8.46)^{* *}\end{array}$ & $\begin{array}{c}4.21 \\
(2.66-8.48)^{* *}\end{array}$ & $\begin{array}{c}4.59 \\
(2.79-8.54)^{* *}\end{array}$ \\
\hline $\begin{array}{l}\text { Maternal social support } \\
\text { (ref: support) }\end{array}$ & $\begin{array}{c}3.30 \\
(1.56-5.98)^{*}\end{array}$ & $\begin{array}{c}1.58 \\
(0.7-3.56)\end{array}$ & $\begin{array}{c}2.25 \\
(1.09-4.6)\end{array}$ & $\begin{array}{c}1.36 \\
(0.65-2.88)\end{array}$ & $\begin{array}{c}2.1 \\
(0.96-4.5)^{*}\end{array}$ \\
\hline
\end{tabular}

Logistic regression models

OR=odds ratios; $95 \%$ CI $=95 \%$ confidence intervals.

Other variables included in the model are: mother's age, mother's education, residence, family type (nuclear or extended), parity and sex of child.

${ }^{*} \mathrm{P}<0.01{ }^{* *} \mathrm{P}<0.001$ 
social scale, which was consistent with other results that previously identified maternal social support as a protective factor for child development outcomes $(21,22)$. Primary care, public health, prenatal and parenting programmes could inform parents about the importance of establishing a social support network.

Parents, caregivers and families need to be supported in providing care and protection for young children in order help them achieve their developmental potential. The intervention packages should be applied at developmentally appropriate times during the life course, target multiple risks, and build on existing delivery platforms for feasibility of scale-up (23). If children with developmental delays or disabilities and their families are not provided with timely and appropriate early intervention, support and protection, their difficulties can become more severe, often leading to lifetime consequences, increased poverty and profound exclusion (24).

\section{Limitations}

Our study has a number of limitations, including missing mothers and their children in the end line survey, and subjective nature of questions in ASQ-3. However, this last problem was mitigated by explanations offered by the researcher.

\section{Conclusions}

This study's results revealed the impact of maternal health education in improvement of early childhood developmental domains. Designing educational interventions in routine healthcare services that reach all children, and provide policy mechanisms for sustainability of the programme, will provide mothers with the opportunity for improvement of early childhood developmental and allow for early diagnosis of child development disorders.

Funding: None.

Competing interests: None declared.

\section{Impact d'un programme de formation des mères sur le développement du jeune enfant en Égypte}

\section{Résumé}

Contexte: Les premières années de vie, en particulier les deux premières années, sont considérées comme les plus importantes pour le développement du cerveau et les interventions en temps opportun affectent profondément la santé de l'enfant et des familles.

Objectifs : La présente étude visait à déterminer l'impact de l'éducation sanitaire des mères sur le développement moteur, social et cognitif des nourrissons de moins de deux ans, et à identifier les facteurs susceptibles d'affecter leur développement normal.

Méthodes : 210 mères et leurs nourrissons (109 interventions, 101 témoins) ont été recrutés dans les centres de santé maternelle et infantile (SMI) du gouvernorat d'Assiout (Égypte) en 2017. Le programme de formation des mères a été dispensé aux mères de nourrissons dans les groupes d'intervention deux fois par mois et pour une durée maximale de cinq mois ; cependant, les services systématiques sont fournis uniquement aux groupes témoins. Des analyses bivariées et multivariées ont été réalisées pour identifier les facteurs prédictifs du développement normal les plus importants.

Résultats : Il y a eu des améliorations significatives dans les domaines du développement du jeune enfant pour les groupes d'intervention après cinq mois, comparables à celles de l'évaluation initiale. Le pourcentage de développement normal parmi les groupes d'intervention dans la sous-échelle de communication est passé de 46,8 \% à 76\% puis à 97,9\%, comparativement à 50,5\% à 46,8\% puis à 57,4 \% dans les groupes témoins (évaluation initiale après deux mois et après cinq mois respectivement). L'intervention était un facteur prédictif significatif du développement normal.

Conclusions: Il y a eu une amélioration dans les domaines du développement du jeune enfant pour les groupes d'intervention après l'application du programme de formation des mères. La conception d'interventions éducatives concernant les services de soins de santé généraux qui atteignent tous les enfants offre aux mères l'opportunité d'améliorer le développement du jeune enfant. 


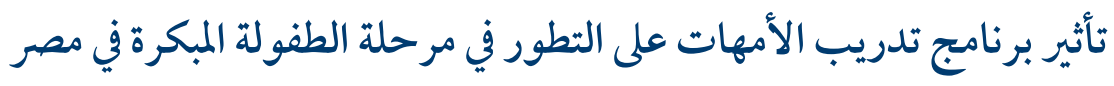

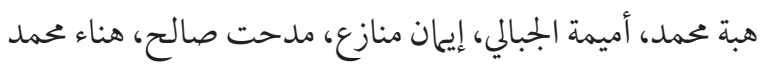

الخلفية: تعد السنوات الأولى من العمر، لا سيّما أول سنتين، الأكثر أهمية لتطور الدماغ، كما تؤثر التدخلات المناسبة بشدة في صحة الطفل والأسرة.

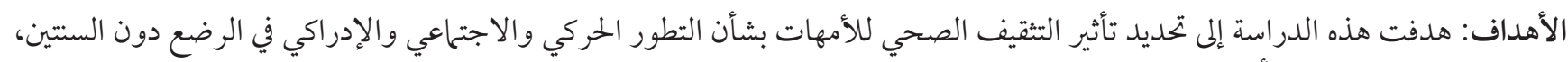
وتحديد العوامل التي يمكن أن تؤثر على التطور الطبيعي.

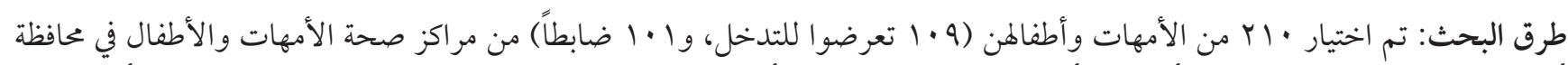

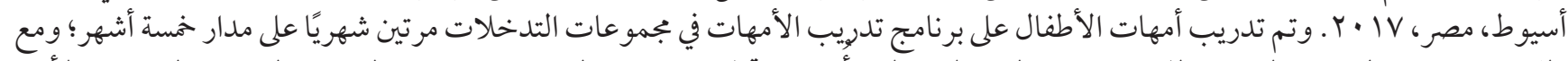

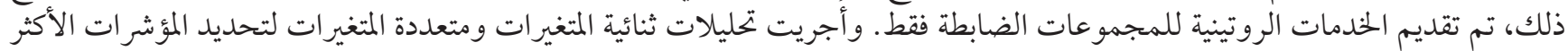

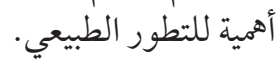

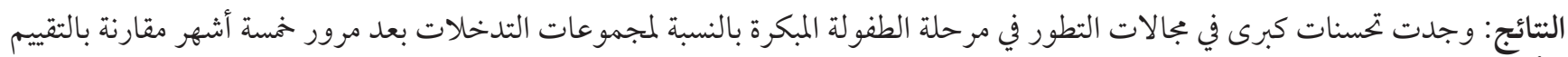

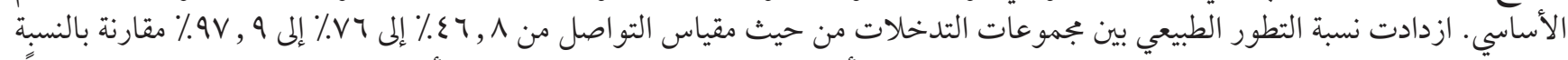

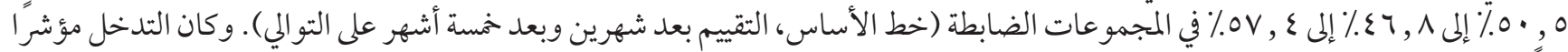
مهاً في التطور الطبيعي.

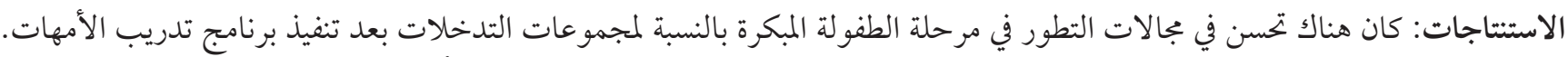

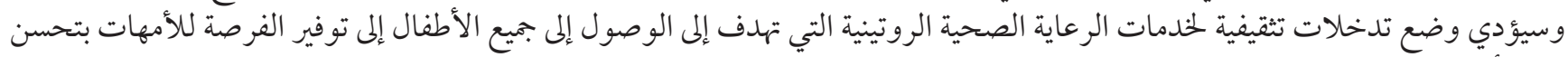
تطور أطفالهن في مرحلة الطفولة المبكرة.

\section{References}

1. Rezaeian A, Niknejad Jalali A, Mazlom S. An investigation of the effect of implementation of evidence-based care package on the gross motor development of the foster care infants. Evidence Based Care Journal. 2013;3(3):69-80 http://dx.doi.org/10.22038/ EBCJ.2013.1800

2. Shevell MI. Present conceptualization of early childhood neurodevelopmental disabilities. J Child Neurol. 2010 Jan;25(1):120-6 http://dx.doi.org/10.1177/0883073809336122

3. Kerstjens JM, Bos AF, ten Vergert EMJ, de Meer G, Butcher PR, Reijneveld SA. Support for the global feasibility of the Ages and Stages Questionnaire as developmental screener. Early Hum Dev. 2009 Jul;85(7):443-7 http://dx.doi.org/10.1016/j.earlhumdev.2009.03.001

4. Nouhjah S, Mokhveli Khazaei F, Mahdavi Zadeh N. Assessment of motor development of children attending health centers of Dezful City using World Health Organization standard indexes. Journal of Paramedical Sciences \& Rehabilitation. 2014;3(1):1626.

5. Boyle CA, Boulet S, Schieve LA, Cohen RA, Blumberg SJ, Yeargin-Allsopp M, et al. Trends in the prevalence of developmental disabilities in US children, 1997-2008. Pediatrics. 2011:peds. 2010-989 http://dx.doi.org/10.1542/peds.2010-2989

6. Anderson LM, Shinn C, Fullilove MT, Scrimshaw SC, Fielding JE, Normand J, et al. The effectiveness of early childhood development programs: A systematic review. Am J Prev Med. 2003 Apr;24(3 Suppl):32-46 http://dx.doi.org/10.1016/So749-3797(02)00655-4

7. Shipra N, Shubhangna S. Influence of intervention on temperament and developmental outcomes of infants. J Hum Ecol. 2009 28(2):121-126 http://dx.doi 10.1080/09709274.2009.11906227

8. Eickmann SH, Lima ACV, Guerra MQ, Lima MC, Lira PIC, Huttly SRA, et al. Improved cognitive and motor development in a community-based intervention of psychosocial stimulation in northeast Brazil. Dev Med Child Neurol. 2003. Aug;45(8):536-41: http://dx.doi/10.1017/s0012162203000987

9. Kynø NM, Ravn IH, Lindemann R, Fagerland MW, Smeby NA, Torgersen AM. Effect of an early intervention programme on development of moderate and late preterm infants at 36 months: a randomized controlled study. Infant Behav Dev. 2012 Dec;35(4):916-26 http://dx.doi/10.1016/j.infbeh.2012.09.004

10. Limbos MM, Joyce DP. Comparison of the ASQ and PEDS in screening for developmental delay in children presenting for primary care. J Dev Behav Pediatr. 2011 Sep;32(7):499-511 http://dx.doi/10.1097/dbp.obo13e31822552e9

11. Hornman J, Kerstjens JM, de Winter AF, Bos AF, Reijneveld SA. Validity and internal consistency of the Ages and Stages Questionnaire 6o-month version and the effect of three scoring methods. Early Hum Dev. 2013 Dec;89(12):1011-5 http://dx.doi/10.1016/j. earlhumdev.2013.08.016

12. Twombly E, Fink G. Ages and Stages learning activities: Baltimore, MD: PH Brookes Publishing; 2004.

13. Ahmadi J, Ahmadi Doulabi M, Sajedi F, Nasiri M. The Effect of Care Package on Motor Development among 12-Month-Old In- 
fants in Saqqez-Iran: A Randomized Clinical Trial Study. Int J Pediatr 2017 5(8):5571-82 http://dx.doi/10.22038/IJP.2017.23461.1974

14. Miquelote AF, Santos DC, Caçola PM, Montebelo MIdL, Gabbard C. Effect of the home environment on motor and cognitive behavior of infants. Infant Behavior and Development. 2012;35(3):329-34 http://dx.doi/10.1016/j.infbeh.2012.02.002

15. Kosari S, Hemayat-Talab R, Arab-Ameri E, Keyhani F. The effect of physical exercise on the development of gross motor skills in children with attention deficit/hyperactivity disorder. Zahedan Journal of Research in Medical Sciences. 2013;15(2):74-8.

16. Kyerematen V, Hamb A, Oberhelman RA, Cabrera L, Bernabe-Ortiz A, Berry SJ. Exploratory application of the Ages and Stages (ASQ) child development screening test in a low-income Peruvian shantytown population. BMJ open. 2014;4(1):e004132 http:// dx.doi/10.1136/bmjopen-2013-004132

17. Sajedi F, Vameghi R, Kraskian Mujembari A. Prevalence of undetected developmental delays in Iranian children. Child Care Health Dev. 2014 May;40(3):379-88 http://dx.doi/10.1111/cch.12042

18. Alptekin K, Ulas H, Akdede BB, Tümüklü M, Akvardar Y. Prevalence and risk factors of psychotic symptoms: in the city of Izmir, Turkey. Soc Psychiatry Psychiatr Epidemiol. 2009 Nov;44(11):905-10 http://dx.doi/10.1007/s00127-009-0012-x

19. Alvik A, Grøholt B. Examination of the cut-off scores determined by the Ages and Stages Questionnaire in a population-based sample of 6 month-old Norwegian infants. BMC pediatrics. 2011;11(1):117 http://dx.doi/10.1186/1471-2431-11-117

20. EL-Ella SSA, Tawfik MAM, Barseem NF, Elatabany AMAM. Assessment of intellectual development in preschool children in the East of Menoufia Governorate, Egypt. Menoufia Medical Journal. 2017;30(3):741 http://dx.doi/10.4103/1110-2098.218257

21. Cabaj JL, McDonald SW, Tough SC. Early childhood risk and resilience factors for behavioural and emotional problems in middle childhood. BMC pediatrics. 2014;14(1):166 http://dx.doi/10.1186/1471-2431-14-166

22. McDonald SW, Kehler HL, Tough SC. Protective factors for child development at age 2 in the presence of poor maternal mental health: results from the All Our Babies (AOB) pregnancy cohort. BMJ open. 2016;6(11):e 012096 http://dx.doi/10.1136/bmjopen-2016-012096

23. Britto PR, Lye SJ, Proulx K, Yousafzai AK, Matthews SG, Vaivada T, et al. Nurturing care: promoting early childhood development. Lancet. 2016;389(10064):91-102. http://dx.doi.org/10.1016/S0140-6736(16)31390-3

24. World Health Organization, UNICEF. Early childhood development and disability: discussion paper. Geneva \& New York: WHO \& UNICEF; 2012. 